\title{
Balanced harvest: concept, policies, evidence, and management implications
}

\author{
Shijie Zhou $($ ) Jeppe Kolding $(\mathbb{D} \cdot$ Serge M. Garcia • Michael J. Plank • \\ Alida Bundy • Anthony Charles $(\mathbb{D} \cdot$ Cecilie Hansen $\cdot$ Mikko Heino • \\ Daniel Howell • Nis S. Jacobsen - David G. Reid · Jake C. Rice - Paul A. M. van Zwieten
}

Received: 14 May 2018/Accepted: 23 April 2019/Published online: 11 June 2019

(C) The Author(s) 2019

\begin{abstract}
Balanced harvest has been proposed to reduce fishing impact on ecosystems while simultaneously maintaining or even increasing fishery yield. The concept has attracted broad interest, but also received criticisms. In this paper, we examine the theory, modelling studies, empirical evidence, the legal and policy frameworks, and management implications of balanced harvest. The examination reveals unresolved issues and challenges from both scientific and management perspectives. We summarize current
\end{abstract}

\section{S. Zhou $(\bowtie)$}

CSIRO Oceans and Atmosphere, 306 Carmody Road,

St. Lucia, Brisbane, QLD 4067, Australia

e-mail: Shijie.Zhou@csiro.au

J. Kolding $(\varangle) \cdot$ M. Heino

Department of Biological Sciences, University of Bergen, PO Box 7803, 5020 Bergen, Norway

e-mail: jeppe.kolding@uib.no

J. Kolding - S. M. Garcia - A. Charles - J. C. Rice IUCN Commission of Ecosystem Management, Fisheries Expert Group (IUCN-CEM-FEG), Gland, Switzerland e-mail: grcsgm@gmail.com

M. J. Plank

School of Mathematics and Statistics and Te Pūnaha Matatini, University of Canterbury, Christchurch 8140, New Zealand

e-mail: michael.plank@canterbury.ac.nz knowledge and address common questions relevant to the idea. Major conclusions include: balanced harvest can be expressed in several ways and implemented on multiple levels, and with different approaches e.g. métier based management; it explicitly bridges fisheries and conservation goals in accordance with international legal and policy frameworks; modelling studies and limited empirical evidence reveal that balanced harvest can reduce fishing impact on ecosystem structure and increase the aggregate yield; the

\author{
A. Bundy \\ Fisheries and Oceans Canada, Bedford Institute of \\ Oceanography, PO Box 1006, Dartmouth, NS B2Y 4A2, \\ Canada \\ A. Charles \\ School of Business and School of the Environment, Saint \\ Mary's University, Halifax, NS B3H3C3, Canada \\ C. Hansen · M. Heino $\cdot$ D. Howell \\ Institute of Marine Research, PO Box 1870, \\ 5817 Nordnes, Bergen, Norway \\ M. Heino \\ International Institute for Applied Systems Analysis \\ (IIASA), 2361 Laxenburg, Austria \\ N. S. Jacobsen \\ School of Aquatic and Fisheries Science, University of \\ Washington, Seattle, WA, USA \\ D. G. Reid \\ Institute of Marine Research, Galway, Ireland
}


extent of balanced harvest is not purely a scientific question, but also a legal and social choice; a transition to balanced harvest may incur short-term economic costs, while in the long-term, economic results will vary across individual fisheries and for society overall; for its application, balanced harvest can be adopted at both strategic and tactical levels and need not be a full implementation, but could aim for a "partiallybalanced" harvest. Further objective discussions and research on this subject are needed to move balanced harvest toward supporting a practical ecosystem approach to fisheries.

Keywords Ecosystem approach to fishery . Ecological effect - Ecosystem structure $\cdot$ Fishing intensity $\cdot$ Production $\cdot$ Selectivity $\cdot$ Sustainability

\section{Introduction}

The harvesting of aquatic organisms for direct or indirect human consumption is arguably the most important provisioning service that the world's waters deliver to our society. Production from fishing supports the UN Sustainable Development Goals (SDGs, https://sustainabledevelopment.un.org) by alleviating poverty (SDG1), particularly for underprivileged people, and providing food and nutrition security (SDG2 and 3) for millions of people around the world. However, fishing activities often have drastic and deleterious effects on aquatic ecosystems, including depletion of commercial stocks, truncation of size and structures, loss of genetic diversity within a species, and changes in the species composition in an ecosystem. This can lead to loss of potential food resources, habitat, and employment, jeopardizing the goal of conserving and sustainably using the marine resources (SDG14).

J. C. Rice

Fisheries and Oceans, 200 Kent Street, Stn. 12S015,

Ottawa, ON K1A OE6, Canada

P. A. M. van Zwieten $(\square)$

Aquaculture and Fisheries Group, Wageningen

University, PO Box 338, 6700 AH Wageningen,

The Netherlands

e-mail: paul.vanzwieten@wur.nl
The concept of balanced harvest has been proposed to reduce fishing impact on ecosystems while simultaneously increasing food production (Zhou et al. 2010; Garcia et al. 2012). Balanced harvest means applying a moderate fishing intensity across as much of the ecosystem as feasible, spreading the load in proportion to each taxa's production instead of putting pressure on particular, selected taxa or sizes. The concept has attracted broad interest worldwide, spawning four international symposia (Garcia et al. 2011, 2014; Heath et al. 2017; https://afs.confex.com/ afs/2014/webprogram/Session3011.html, two journal special issues (He et al. 2016; Kolding et al. 2016b), and a range of papers in scientific journals. While balanced harvest is proposed to be a potentially valuable strategy for ecosystem-based fisheries management (EBFM), a number of questions, critiques and requests for clarifications on balanced harvest have been raised since its appearance (for example, Tweddle et al. 2015, Andersen et al. 2016; Breen et al. 2016; Burgess et al. 2016; Froese et al. 2016; Pauly et al. 2016). Key concerns include:

(1) The goals of balanced harvest and associated terminology (e.g., selective and unselective fishing, productivity and production) are unclear;

(2) Balanced harvest is incompatible with the stated missions of major international organisations such as the FAO and IUCN on selective fishing and protection of threatened species;

(3) Some ecosystem models do not support balanced harvest and size-spectrum models are highly unrealistic;

(4) There is a lack of empirical evidence to support balanced harvest because it has not yet been explicitly implemented by any management authority;

(5) Minimum size limits are essential for sustainable fishery management. Harvesting young fish exaggerates the effect of size truncation rather than alleviating the effect;

(6) Increasing fishing intensity on some ecological groups such as forage fish or marine mammals is unacceptable;

(7) Balanced harvest is economically infeasible or would reduce overall profitability as it would incur significant costs while harvesting low- 
value components and may lead to reductions in harvest of high value species;

(8) Balanced harvest would lead to significant ecological costs as it reduces biomass of all ecological groups;

(9) It may be difficult to fully implement balanced harvest as it would require detailed biological knowledge of each ecological group as well as a coherent policy.

This paper aims to clarify the concept of balanced harvest and to address some of these issues. Clearly, there may be more questions surrounding balanced harvest and the discussion is ongoing. This paper does not intend to address every critique in detail individually, rather we attempt to objectively summarize current knowledge.

The following sections examine successively the concept of balanced harvest, the models used for its analysis, the empirical evidence available, the legal and policy frameworks within which balanced harvest would operate, economic considerations, and the management implications. The paper ends with key conclusions relevant to the questions listed above and a discussion of remaining scientific issues that require further research.

\section{The concept of balanced harvest}

\section{Definitions}

To help readers better understand the balanced harvest concept we first provide the definitions for the terms used in this paper (Table 1).

\section{Goals of balanced harvest}

The balanced harvest concept was motivated by widespread problems caused by conventional fishing practices and management: overfishing of target species (Costello et al. 2012; Sumaila et al. 2012), decrease of global catch (FAO 2016), depletion of large predatory species but increasing abundance of small prey fish (Christensen et al. 2014), and agetruncation and potential fisheries-induced evolution (Heino and Godø 2002; Law 2007; Hsieh et al. 2010). The concept was developed in response to the ecological challenge of maintaining ecosystem structure (CBD 1998) and the biological challenge of maintaining long-term sustainable yields and avoiding overfishing (United Nations [UN] 1982). The goals of balanced harvest have been extensively discussed (Bundy et al. 2005; Zhou et al. 2010, 2015, Law et al. 2012, 2013, 2016, Garcia et al. 2012, 2016a, Jacobsen et al. 2014, 2017; Charles et al. 2016, Kolding et al. 2016b). In short, balanced harvest simultaneously aims to: (1) minimize significant adverse fishing impact on the relative size and species composition of aquatic ecosystems, thereby minimising impacts on ecosystem structure and functioning, and (2) increase or maintain sustainable yield from such ecosystems (with no attempt to maximize yield by ignoring the first goal).

Interpretation of balanced harvest

The concept of balanced harvest has two key components: goals and strategy. It is a proposed approach that is characterized by its particular attention to tackling the problem of fishing impact on ecosystem structure and community composition. It is important to note that the strategy proposed in balanced harvest (1) refers to a balanced fishing mortality at the ecosystem or community level rather than at an individual gear or fleet level, and (2) fishing mortality proportional to production is a special type of selective fishing and is not (and does not promote) indiscriminate or unselective fishing as interpreted in some literature (Pauly et al. 2016). For example, under the balanced harvest definition, populations of species depleted by excessive fishing would be rebuilt and then maintained at the level commensurate with their production.

\section{Legal and policy considerations}

Balanced harvest aims to simultaneously address the legal requirements of the United Nations Convention on the Law of the Sea (UNCLOS)—no overfishing, and the UN Convention on Biological Diversity (CBD) - maintain ecosystem structure and function. The 1982 UNCLOS requires that target stocks be kept at the "level which can produce the Maximum Sustainable Yield (MSY) as qualified by relevant ecological and socioeconomic factors" ( $\$ 61.3$ and 119.1a). For non-target species, UNCLOS requires "maintaining or restoring populations... above levels 
Table 1 Definitions for the terms used in this paper

\begin{tabular}{|c|c|}
\hline Term & Description \\
\hline Ecological group/component & $\begin{array}{l}\text { A set of ecological elements with similar properties, e.g., species, sex, age, sizes, size-groups } \\
\text { within species or species with similar ecological attributes }\end{array}$ \\
\hline Production $(P)$ & $\begin{array}{l}\text { The total cumulated new biomass produced from an ecological group during a given period, } \\
\text { irrespective of its fate, expressed as biomass time }{ }^{-1} \text {. Production and surplus (net) production are } \\
\text { sometimes used interchangeably in fisheries. Surplus production is production (somatic growth } \\
\text { plus recruits) less mortality. In this paper, production refers to gross production without } \\
\text { subtracting mortality }\end{array}$ \\
\hline Productivity $(p)$ & $\begin{array}{l}\text { The gross production per biomass unit of an ecological group during a given period }(\mathrm{P} / \mathrm{B}) \text {. } \\
\text { Productivity has a unit of time } \mathrm{e}^{-1} \text {. It corresponds to the rate of natural population increase of the } \\
\text { group and, under steady state conditions, also the instantaneous total mortality rate. Productivity } \\
\text { may vary between ecological groups and within each ecological group itself. For each ecological } \\
\text { group, productivity is a function of its own density and its prey's density. Across ecological } \\
\text { groups, productivity is determined by life history traits }\end{array}$ \\
\hline Fishing intensity & The amount of fishing effort applied per unit area per unit time \\
\hline Fishing mortality or death $(D)$ & $\begin{array}{l}\text { A measure of total fishing-induced death in number or weight as the sum of landed catch, fish } \\
\text { discarded that do not survive, and unobserved death of a specific ecological group in a given } \\
\text { period. Fishery yield is often used as an approximate for fishing mortality when discards and } \\
\text { unobserved death are ignored }\end{array}$ \\
\hline Fishing mortality rate $(F)$ & $\begin{array}{l}\text { A measure of total fishing-induced death in number or weight in an ecological group scaled to the } \\
\text { mean number or biomass of that group in a given period. } F \text { is also called instantaneous rate of } \\
\text { fishing mortality }\end{array}$ \\
\hline $\begin{array}{l}\text { Conventional fishery } \\
\text { management (CFM) }\end{array}$ & $\begin{array}{l}\text { CFM focuses on single species or stock management, aims at maintaining stocks at an MSY-related } \\
\text { level, taking incomplete account of ecological structure and community interactions. At fleet } \\
\text { level, using the same type of gear, conventional fishing can be highly selective by targeting a } \\
\text { small group of organisms (either by species, sex, or size). At ecosystem level, CFM targets a } \\
\text { wider range of organisms using various gear types but still avoids many low valued or } \\
\text { emblematic groups }\end{array}$ \\
\hline $\begin{array}{l}\text { Selective (or unselective) } \\
\text { fishing }\end{array}$ & $\begin{array}{l}\text { Selective (or unselective) fishing is a fishing activity that results in a systematic difference (or } \\
\text { similarity) between the composition of the biotic resources and the composition in the catch. The } \\
\text { difference, materialized in a selectivity curve, is usually established at the level of the gear, } \\
\text { vessel, or fleet (métier). In balanced harvest, selectivity is considered at the ecosystem level and } \\
\text { is the cumulative result of the selectivity of all fleets operating within the ecosystem }\end{array}$ \\
\hline Balanced harvest $(\mathrm{BH})$ & $\begin{array}{l}\text { Initially described as a fishery management strategy "distributing a moderate fishing pressure } \\
\text { across the widest possible range of species, stocks, and sizes of animals within an ecosystem, in } \\
\text { proportion to their natural productivity so that the relative size and species composition is } \\
\text { maintained" (Garcia et al. 2012). Using elements present in this definition and elaborating on it, } \\
\text { balanced harvest could be rephrased as: the management strategy and collective fishing activities } \\
\text { that impose moderate fishing mortality on each utilisable ecological group in proportion to its } \\
\text { production, to support long-term total sustainable yields while minimizing fishing impact on the } \\
\text { relative species, size, and sex composition within an ecosystem }\end{array}$ \\
\hline
\end{tabular}

at which their reproduction may become seriously threatened" ( $\$ 61.4$ and 119.1b). The 1995 UN Fish Stock Agreement (UNFSA), for precautionary reasons related to assessment uncertainties and predator-prey relationships, re-qualified MSY as the upper allowable limit to exploitation while maintaining UNCLOS requirement for non-target species.

The 1992 CBD aims at conservation of biological diversity and sustainable use of its components. It also calls for maintenance and recovery of viable populations of species (Art. 2). Its ecosystem approach states that conservation of ecosystem structure and functioning ... should be a priority target (CBD 1998) and the 2004 Addis Ababa Principles for Sustainable Use (Decision VII/12) state that parties should avoid or minimize adverse impacts on ecosystem services, structure and functions. 
The UNCLOS and UNFSA do not refer to ecosystem structure and the CBD does not refer to MSY, but it should be implemented consistent with the rights and obligations of States under the law of the sea (CBD Art. 22.2). The 1995 Code of Conduct for Responsible Fisheries (CCRF) and the ecosystem approach to fisheries (EAF) (FAO 2003) provided a level of integration between UNCLOS and the CBD, operationalizing to some extent the need to maintain ecosystem structure and function, without proposing a norm to that effect. Balanced harvest is intended to contribute to the integration process within the FAO Ecosystem Approach to Fisheries (EAF) (Garcia et al. 2014, 2016b). It specifically addresses the fundamental goals of fisheries management and international conventions and policies, including UNCLOS and the related UNFSA, CCRF, CBD, and EAF.

It has been argued, nonetheless, that balanced harvest is incompatible with the mission and policies adopted by FAO around selective fishing and IUCN's red list of threatened species (Pauly et al. 2016). The reality, however, is that balanced harvest integrates explicitly the objectives of sustainable fisheries to avoid overfishing and reproduction failures (in line with FAO policies) and of maintenance of ecosystem structure (in line with the EAF, CCRF and CBD policies).

The difference between balanced harvest and existing fishery policies lies in the strategies proposed to achieve the goals. Like CCRF, balanced harvest recommends using controls on fishing mortality rate (to avoid overfishing) and selectivity (to distribute fishing intensity on species and sizes), but doing so explicitly at ecosystem level, coordinating the fishing patterns of the different métiers to ensure that an appropriate fishing mortality rate is distributed across a wide range of ecological groups, as opposed to concentrating it on a limited number of target species and sizes. As such, balanced harvest implies an adaptation of the conventional implementation strategies, e.g. in relation to more intensive use of productive species, increased protection of old spawners, and reducing the disproportionate changes of ecosystem structure through ecosystem-wide coordination of single-fisheries management regimes.
Technical expression

Technically, balanced harvest can be interpreted in several ways similar to harvest control rules for commercial species when expressed as a relationship between fishing mortality rate $F$ and biomass $B$ for ecological groups (Berger et al. 2012). Alternative expressions hinge on whether fishing mortality rate is proportional to productivity or production and whether the maximum or current productivity is used (Law et al. 2016; Zhou and Smith 2017; Plank 2018). The difference between productivity and production has been discussed in detail at a recent meeting in Scotland (Heath et al. 2017). Productivity varies among ecological groups and is density-dependent. Denoting $p$ as current productivity (unit $\mathrm{yr}^{-1}$ ), $p_{\max }$ as maximum productivity at very low density (i.e., available food per capita is unlimited), and $P$ as current production $\left(P=p B\right.$, unit weight $\left.\mathrm{yr}^{-1}\right)$, for each ecological group $g$, balanced harvest can be expressed in at least three forms (Fig. 1):

(i) $F_{g}$ proportional to maximum productivity: $F_{g}=c p_{\max , g}\left(\mathrm{yr}^{-1}\right)$ and $Y_{g}=F_{g} B_{g}=c p_{\max , g-}$ $B_{g}$ (weight $\mathrm{yr}^{-1}$ );

(ii) $F_{g}$ proportional to current productivity: $F_{g}=c p_{g}$, and $Y_{g}=F_{g} B_{g}=c p_{g} B_{g}$;

(iii) $F_{g}$ proportional to current production: $F_{g}=c P_{g}=c p_{g} B_{g}$, and $Y_{g}=F_{g} B_{g}=c p_{g} B_{g}^{2}$.

In forms (i) and (ii), $c$ is a fraction of maximum or current productivity and is a dimensionless constant between 0 and 1 for all ecological groups considered for balancing; in form (iii), $c$ is a coefficient of current production, has a dimension biomass ${ }^{-1}$ and is not constrained to be between 0 and 1 . Because of its dependence on biomass, this form is similar to the "hockey stick", "sliding" or "state-dependent" harvest control rule for target species (Berger et al. 2012). In these forms, the quantities of $p_{g}, P_{g}$, and $B_{g}$ are also affected by other ecological groups through ecological interactions. The rules of fishing mortality rate may work together with a limit placed for biomass, i.e., setting $F_{g}=0$ when $B_{g}$ is less than a fixed fraction of unfished biomass $B_{O g}$. When applying a particular form to each ecological group, the key is to define a constant $c$, the target fishing intensity (see Target fishing mortality rate section below) for all groups. Differences exist between the alternative forms, in terms of fisheries yield, ecological impact, and 

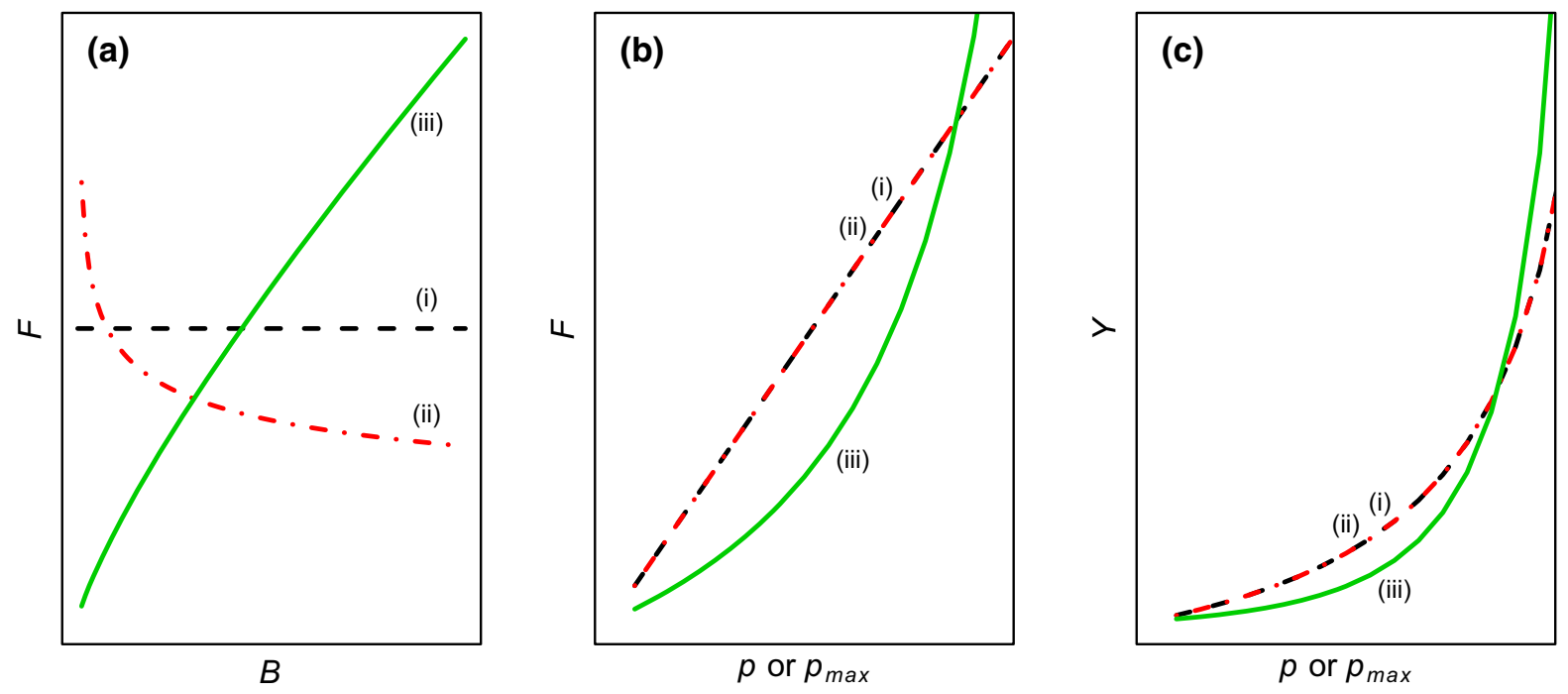

Fig. 1 Illustration of alternative interpretations of balanced harvest for a specific ecological group (e.g., species) (a) and between groups $(\mathbf{b}, \mathbf{c})$. Productivity is assumed to be densitydependent. (i) Fishing mortality rate $F$ proportional to maximum

implementation complexity. Consequences of applying these forms have been theoretically explored using size-based models and multispecies interaction models (Law et al. 2016; Heath et al. 2017; Zhou and Smith 2017; Plank 2018). Further research and additional modelling techniques should be performed to fully understand the trade-offs between alternative approaches.

Implementation becomes more difficult from form (i) to (iii). At species level, form (i) is comparable to $F \propto F_{\text {msy }}$ or $F \propto M$, the constant harvest control rule, while the yield is adjusted by species interactions through change in biomass. Species-specific $p_{\max }$ is analogous to the intrinsic rate of natural increase $\left(r_{m}\right)$ and related to life-history traits and its proxy may be derived from life-history correlations. This form allows $F$-based management to be implemented without knowing biomass or biomass trends (e.g., $F$ can be estimated by catch-curve, length-based, or area-based methods) (Geromont and Butterworth 2015). In Form (ii), current productivity $(P / B$ or $p$ ) may be estimated from total mortality $(Z)$ under steady state assumptions (Paloheimo and Dickie 1970; Allen 1971). However, knowledge of biomass is required for setting $F$ reference points in Form (iii), which will hinder its routine implementation for a wide range of ecological groups in many ecosystems. productivity $p_{\max }$ measured at low biomass density $B$; (ii) Fishing mortality rate proportional to current productivity $p$ that declines as density increases; (iii) Fishing mortality rate proportional to current production $(P=p B) . Y$ in $\mathbf{c}$ is yield

Balanced harvest on species and sizes

Balanced harvest can take place at least at two possible levels. First, species-level balanced harvest (sBH) balances fishing mortality across the widest possible range of species within an ecosystem, including currently non-targeted species. Second, species- and size-level balanced harvest (ssBH) balances fishing mortality on the widest possible range of species and sizes within species. Note that balanced harvest does not suggest to ignore species and only balance fishing mortality by size alone, as has been sometimes suggested (e.g. Pauly et al. 2016). Species is the basic taxonomic unit in biodiversity conservation and fisheries management. Productivity is species- and size-dependent. Applying a fishing mortality rate solely based on average productivity of each size group could lead to depletion of species with low production, against the goals of balanced harvest.

From an ecosystem point of view, the principle of $\mathrm{sBH}$ is not completely new. It is an ecosystemic extension of conventional fisheries management that distributes fishing mortality on both commercial and currently non-targeted species. Nor are attempts to account for ecological interactions new (e.g., May et al. 1979), though the established norm (MSY) is largely stock-based. The extension of the concept to 
ssBH does explicitly require additional information about how productivity varies with size, which means that ssBH deserves more research and would require more information to implement and more management coordination within the ecosystem than $\mathrm{sBH}$.

\section{Balanced harvest species coverage}

The question of which ecological components should be exploited is a sensitive one. Balanced harvest implies harvesting the widest possible range of ecological groups, which emphasises the science pertinent to ecological goals that are widely accepted and legally mandated. However, the reality of fishing as an economic and social activity recognized by the UNCLOS affects the way the law is implemented. There are practical difficulties and economic disadvantages in harvesting organisms at very low trophic levels (such as zooplankton) or of very low commercial value (e.g. species with high levels of toxins); there are also political constraints and ethical reservations in harvesting some top predators. These concerns differ from region to region. For example, some societies value certain groups or species (such as marine mammals) as emblematic (to be protected), while other societies hunt them, and yet others may wish to reduce or completely remove them (such as culling seals that have depleted fish populations, or killing dangerous sharks). Similarly, in some regions, one goal (e.g. food security or human safety) may be considered more important than others (e.g., ecosystem structure, cultural identity, or rent extraction) and trade-offs exist between them. Hence, the principle of ecosystem conservation needs to be tuned to local legal and societal needs and preferences. While science can provide information on the implications of drawing the boundaries (from plankton to whales) at different points in the food web (Burgess et al. 2016; Howell et al. 2016; Pauly et al. 2016), the extent of ecological groups to be harvested is ultimately both a legal question and a societal choice (Garcia et al. 2016a), and one that is further constrained by technical limitations.

Target fishing mortality rate and long-term total yield

Balanced harvest does not recommend reducing the biomass of all ecological groups to a severely low level, as interpreted in some literature (Burgess et al. 2016; Froese et al. 2016). In fact, for the same amount of yield, balanced harvest may lead to higher total biomass than conventional fishing because fishing mortality is spread to more productive species, often at lower trophic levels (TLs), so it reduces biomass and energy losses during transfer to higher TLs that are disproportionately targeted under conventional fishing. However, unlike in UNCLOS and CCRF, a target fishing mortality rate has rarely been explicitly defined or recommended in balanced harvest. Existing modeling studies have used combinations of a range of fishing mortality rates and alternative selectivity patterns to investigate the effect of fishing intensity and selectivity (e.g., Bundy et al. 2005; Law et al. 2012, 2013; Jacobsen et al. 2014; Zhou and Smith 2017). For model formulations with density-dependent dynamics, there is a maximum total yield from multiple trophic levels while the community structure can be largely maintained (Jacobsen et al. 2014; Zhou and Smith 2017; Plank 2018). In addition to these recent studies, ecosystem-based reference functions have been proposed by using percentage of primary production required to sustain fisheries and the average trophic level of catch (Tudela et al. 2005; Coll et al. 2008; Libralato et al. 2008). Using this approach, a reference point called ecosystem-based maximum sustainable catches (EMSC) has been developed. The UNCLOS sets the biomass at MSY as a possible management target, as qualified by relevant environmental and economic factors. Therefore, it would be in the spirit of this legislation to use fishing mortality rate corresponding to EMSC or the ecosystem-wide maximum sustainable yield (EMSY, if it could be calculated) as a limit reference point under balanced harvest rather than as a target (Rindorf et al. 2017a; Trenkel 2018). This recommendation recognizes the limitation of MSY based on singlespecies and the importance of considering other management goals in estimating EMSY (Larkin 1996; Rindorf et al. 2017b).

From a total yield perspective, EMSY is meaningless if ecosystem structure is not considered as a constraint because yield could be maximized by eliminating all predators. Balanced harvest recognizes the importance of both goals and suggests to maintain or increase total yield by expanding fisheries to include species that are typically at lower TLs (and often low-valued), more abundant and more 
productive. On the other hand, whether expanding fisheries to harvest juveniles can increase total yield is an ongoing debate (see "Modelling studies").

\section{Impact on ecosystem structure}

The ecosystem structure can be defined at several levels, e.g., species, trophic level, and functional groups, but it commonly refers to species composition (MRAG \& UNEP-WCMC 2008). From a fishery management point of view, here we interpret that maintaining ecosystem structure means maintaining to the greatest extent possible the quantitative and qualitative relations between the groups as overall biomass decreases under harvesting (i.e., it does not refer to the absolute biomass of each groups as it is impossible to fish without changing biomass).

The legally mandated CBD goal of "maintaining ecosystem structure and function" has not been genuinely tackled by any fishery management scheme except balanced harvest. International and national instruments, including EBFM, treat commercial and non-commercial species differently, at least in principle: the former is mechanically discriminated (targeted to be fished at some MSY level) while the latter is avoided as much as possible and labelled as bycatch. Selective fishing, as implemented by CFM, has changed ecosystem structure and will continue to do so in most fisheries. There has been progress towards increasing the range of target species in existing fisheries, an unintentional move toward balanced harvesting.

Fishing also distorts age and size structure within a species. It has been argued that excessive fishing mortality, rather than selective targeting of large sizes, leads to age and size truncation of exploited populations (Froese et al. 2016). However, age and size structure within a species is shaped by both fishing mortality rate and selectivity. For example, for the same level of fishing mortality, gillnet fishing leaves a larger fraction of old spawners unharvested than does trawling (Jørgensen et al. 2009; Wolff et al. 2015). Although the importance of conserving old spawners (BOFFFFs; Hixon et al. 2014) in fished populations is well known, the implications of harvesting immature fish, taking account of predator-prey relations, deserve more research.

\section{Modelling studies}

The consequences of balanced harvest have been evaluated in various models, including models of sBH (Garcia et al. 2012; Kolding et al. 2016a; Zhou and Smith 2017; Plank 2018) and ssBH (Jacobsen et al. 2014; Law et al. 2016).

Distribution of production across age and body size

One controversial aspect of balanced harvest has been the suggestion in some studies that fisheries should target small-sized and juvenile fish in contrast to classical fisheries theory (Froese et al. 2016). In fact, $\mathrm{ssBH}$ is consistent with classical yield-per-recruit models (Beverton and Holt 1957) in stipulating that fish should not be harvested before reaching peak cohort biomass (Plank 2017). This is because the production and cohort biomass of a single species always peak at the same age and the same body mass (Law et al. 2016). Figure 2 illustrates this using a simple Beverton-Holt model as an example, but this result applies regardless of the assumptions made about growth and mortality rates.

Production reaches a local maximum at the body size where the per capita mortality rate equals the mass-specific somatic growth rate. In a Beverton-Holt model, growth and mortality rates are externally specified and have only one intersection, meaning there is a single peak in the production that typically occurs relatively late in life (Fig. 2). However, in reality, these rates are variable and determined, at least in part, by predation and fishing. Hence, local maxima in production can occur at more than one body size and are likely to depend on environmental conditions, interactions with other species, and fishing. Some models support the prediction that production peaks relatively late in life (Andersen et al. 2016), but others predict a peak earlier in life (Law et al. 2012). This discrepancy is caused by differences among models in the way density dependence operates (Andersen et al. 2017) and may need to be resolved by empirical research incorporating early life stages.

Nevertheless, the relationships shown in Fig. 2 allow two important conclusions that are robust to specific model assumptions. First, if the onset of fishing pushes the total mortality rate above the massspecific growth rate, this can generate a peak in 
(a)

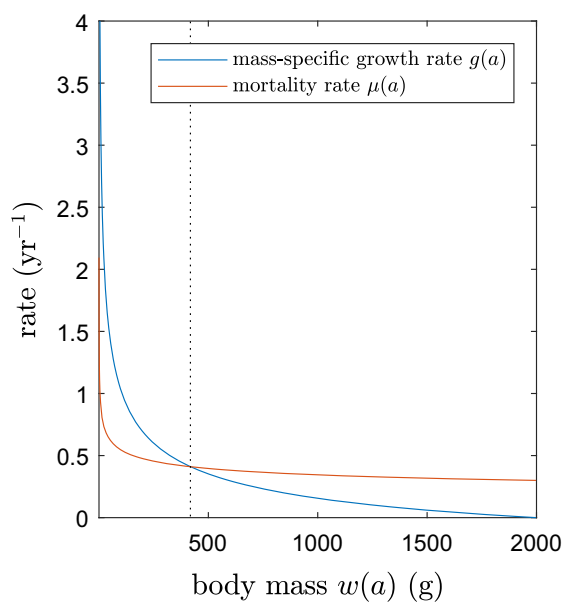

Fig. 2 Relationship between growth, mortality, production and cohort biomass under the example of a standard von Bertalanffy growth model and mortality rate exponentially decreasing with age. a Mass-specific growth rate and mortality rate plotted as functions of body size. b Production and cohort biomass (weight relative to age 0 ) plotted as functions of body size. Production peaks where the mass-specific growth rate and mortality rate intersect (vertical dashed line). Production is proportional to cohort biomass, so the peak cohort biomass and the peak production occur at the same body size. Von Bertalanffy growth model for body mass $w$ at age $a, w(a)=w_{\infty}\left(1-e^{-K\left(a-a_{0}\right)}\right)^{b}$

production near the size at which fish become susceptible to harvest. Fishing, by accident or design, may therefore engineer a local maximum in production, unconnected with the underlying ecosystem structure. Second, production is relatively low at body sizes that are large for their species. At a qualitative level, ssBH calls for low fishing mortality rates that reflect the low production of these large fish, i.e. for dome-shaped or slot-type selectivity rather than sigmoidal selectivity. Reducing fishing mortality at large body sizes has the benefit of protecting large megaspawners (BOFFFFs) in the population (Law 2007; Hixon et al. 2014).

\section{Size-spectrum models}

Size-spectrum models are a natural tool for studying balanced harvest over body size. These models are built around a bookkeeping of biomass as it flows from prey to predator, and from parent to offspring, either in a single species (Benoît and Rochet 2004; Capitan and Delius 2010; Datta et al. 2010) or in multiple interacting species (Andersen and Beyer 2006; (b)

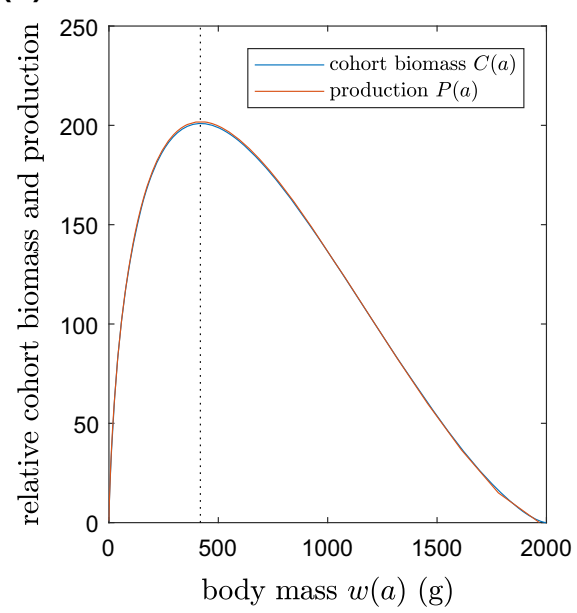

where $K=0.2 \mathrm{yr}^{-1}, w_{\infty}=2000 \mathrm{~g}, a_{0}=-0.2 \mathrm{yr}, \quad b=3$; mortality rate $\mu(a)=\mu_{m}\left(\frac{w(a)}{w_{\infty}}\right)^{-\rho}$ where $\mu_{m}=0.3 \mathrm{yr}^{-1}$, $\rho=0.2$. Mass-specific growth rate is $g(a)=\frac{1}{w} \frac{d w}{d a}$. Cohort biomass at age $a$ is $C(a)=w(a) \exp \left(-\int_{0}^{a} \mu\left(a^{\prime}\right) d a^{\prime}\right)$. Production at age $a$ is $P(a)=u(a) w(a) g(a)$, where $u(a)$ is the equilibrium solution of the McKendrick-von Foerster equation for the abundance of an age-structured population with the specified growth and mortality rates

Hartvig et al. 2011; Scott et al. 2014). These flows allow the production of each size class to be directly calculated. Predation (feeding) is assumed to be the main source of natural mortality, so growth and reproduction rates are dynamically calculated as a function of the abundance of predators and prey. Classical fisheries models typically use externally parameterized growth and natural mortality functions (e.g. von Bertalanffy). These should work under the single-species, food-independent conditions in which the parameter estimates were made, but are not well suited to deal with bigger changes in marine ecosystems, such as those involving changes in size distributions and species composition affecting predation and growth of fish.

Results from size-spectrum models have shown that, relative to targeting only large fish, balancing fishing across body sizes can: (1) reduce the disruption of the natural size structure of populations (Fig. 3); (2) reduce the risk of instability in the population dynamics; and (3) increase the aggregate yield (Law et al. 2012; Jacobsen et al. 2014; Kolding et al. 2016c). It should be noted that this does not imply that 


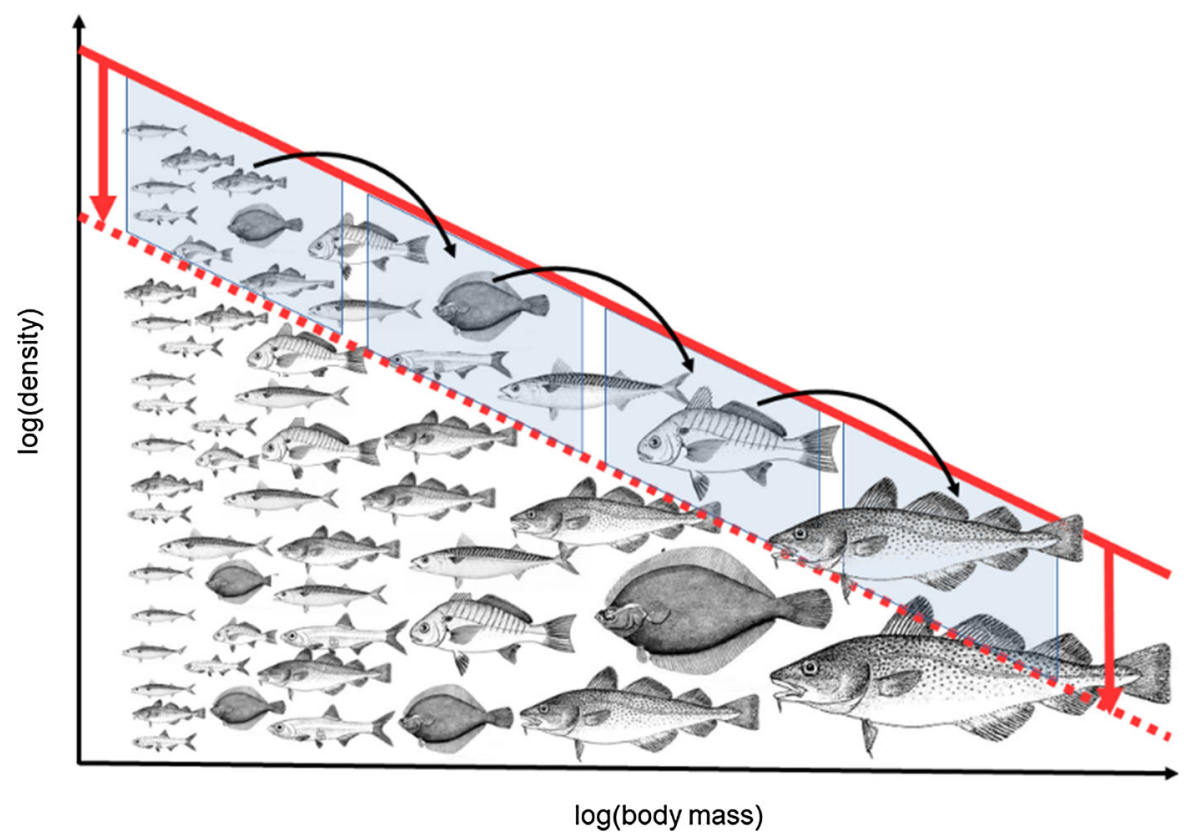

Fig. 3 An idealized equilibrium community size spectrum, showing the relationship between increasing body mass and decreasing density (in log scale) in an unexploited community (solid red). Balanced harvest harvests a cross-section of this size-structured community in proportion to the production; this reduces the overall density, but with relatively little impact on the slope of the exploited size spectrum (dashed red). Balanced

balanced harvest optimizes any of these three objectives, only that it is an improvement relative to exclusively targeting large fish (relative to their asymptotic size). Many EBFM strategies have been suggested or are possible, but only in a few cases has their performance been modelled with sufficient detail to allow comparisons with balanced harvest.

Ecopath with Ecosim (EwE) models

Another modelling framework used to assess ecosystem level fishing is Ecopath with Ecosim (EwE, Christensen and Walters 2004). Ecopath is a static mass balance model, where each component (species or functional group) in an ecosystem is linked through a food web. Ecosim is the dynamical extension, where ecosystem dynamics are projected through time. EwE mainly models species as biomass pools, where the species or group identity (rather than size) is the main structuring factor. However, species or groups can also be modelled by age and size structure (Walters et al. 2010) and in most recent EwE models, a subset of harvest harvests some fish at the highest trophic level, the prey of those fish, the prey of the prey, and so on. As a result, natural predation mortality is replaced by fishing mortality to some degree, so that the total mortality rate is similar to the natural mortality rate in the unexploited state. Note: fish icons are not to scale

functional groups are split into ontogenetic stanzas. In the absence of stanzas, EwE models are primarily equipped for testing the effects of balancing exploitation across species or functional groups $(\mathrm{sBH})$ rather than by size (ssBH).

Garcia et al. (2012) predominantly used EwE models to evaluate the total yield and number of extirpations when only species targeted in an ecosystem were exploited, and when all non-larval nonmicrofauna in the ecosystem were exploited. Models indicated that broadening the pool of exploited species could produce approximately $40 \%$ higher yield, while causing a minimum of extirpations.

A correlation between fishing mortality rate $F$ and production $P$ across species might be expected, even if fishing was not explicitly designed to balance $F$ and $P$ as in Form (iii) $\mathrm{BH}$, because species that are more productive should be able to sustain more intense exploitation. Market preferences for particular species would affect this by increasing $F$ on high-value species (Plank 2017). However, in the only check we know of-an Ecopath model of the West of Scotland 
Shelf ecosystem - there was no relationship between $F$ and $P$ (Heath et al. 2017). If this turns out to be a more general feature of exploited marine ecosystems in market-driven economies, moving in the direction of Form (iii) balanced harvest would be more than just a matter of fine-tuning.

Kolding et al. (2016a) studied 110 Ecopath models from all over the world and compared how even the exploitation ratio $Y / P(=F / Z)$ was across TLs. Form (ii) of $\mathrm{BH}$ would require $Y / P$ to be approximately same for all species, whereas form (iii) would require $Y / P$ to be higher on species with high biomass (Heath et al. 2017). Kolding et al. (2016a) found the reverse: species at low TLs (up to TL 3) tended to have lower $Y / P$ than those at higher TLs (4-5), indicating that the global fishing pattern, as represented in the models, was a long way from being balanced.

\section{Atlantis models}

A third type of model used for exploring balanced harvest is Atlantis (Fulton et al. 2005, 2011), which is a deterministic 'whole of system' model framework. In Atlantis, vertebrate species are typically represented as age-structured, whereas invertebrates are mostly implemented as biomass pools. The components are connected through a flexible diet (availability) matrix, where the predator-prey interaction strengths are defined. However, the availability of prey also depends on its biomass, distribution, individual size and habitat dependency and status. Fisheries can be represented with explicit effort dynamics models or with fishing mortalities that are split by fleet (métier) and applied differentially per age class and species/group, making Atlantis well suited to exploring the combination of size and species. The analysis of Garcia et al. (2012) included two Atlantis models; the results confirmed that broadening the pool of exploited species could produce higher yield and reduce the number of depleted stocks. However, the dynamic nature of production in Atlantis (where reproduction, growth, metabolic costs, nutritional value and access to prey can all be conditiondependent, which in turn depends on feed accessed) highlights some of the challenges of trying to dynamically calculate balanced harvest fishing mortality rates and distributions across species and sizes in practice.
Multispecies predation models

Based on the classic Lotka-Volterra predation equation, a range of multispecies interaction models have been developed and used in fisheries research. Most of the earlier research focused on MSY policy (for example, May et al. 1979) without paying due attention to ecological impact. Using a modified Lotka-Volterra model, McCann et al. (2016) investigated the effect of alternative fishing patterns on yield and species diversity. One particular pattern was "indiscriminate" (i.e., nonselective) fishing because this type of fishery was assumed to be common in developing countries. Their results demonstrated that nonselective fishing modified the fish community in a manner that led to increased productive capacity from a low-diversity assemblage of small-bodied fish with rapid population growth and turnover. The inland fishery in Tonlé Sap, Cambodia (McCann et al. 2016), and fisheries in the East China Sea (Szuwalski et al. 2017) are examples of indiscriminate, relatively nonselective fishing. Though highly productive, the state of these systems are consistent with a trophic cascade in which larger predatory fish have been severely reduced, allowing a greater production rate by small fish. This is quite different from balanced harvest, which calls for conservation of large marine taxa with low production.

These results are consistent with a study using a simple Holling-Tanner predation model (Zhou and Smith 2017). This study applied several fishing strategies across three trophic levels, including selective fishing, nonselective fishing, and balanced harvest. It also tested the effect of selectively harvesting fish at the lowest fishable TL. The results showed that harvesting species at higher TLs had a low impact on total biomass but provided very low yields and had severe impacts on trophic structure. Selectively harvesting the lowest TL reduced the biomass of all fish, resulted in high yields, and was the only strategy that could maintain unfished trophic structure. Nonselective fishing produced high total yield, as shown in the McCann et al. (2016), but could cause extirpation of less productive ecosystem components at high fishing mortality rates, and severely altered the trophic structure. Balanced harvest strategies forms (i) and (ii) produced slightly higher total yield than selectively harvesting the lowest TL, and had a smaller impact on trophic structure than selectively harvesting 
top predators or nonselective fishing, but could not fully maintain trophic structure. This was because when fishing reduced biomass at a lower TL, the available food for fish at higher TLs diminished, leading to a proportional decrease in biomass. On top of this, any additional mortality from fishing, even though in proportion to their production, caused further depletion of higher TLs. Clearly, nonselective fishing and selectively harvesting top predators were not viable options for achieving the two balanced harvest goals. The incapability of fully preserving trophic structure by forms (i) and (ii) of balanced harvest was overcome by form (iii). By applying fishing mortality rate in proportion to production, this type of balanced harvest could maintain trophic structure, with a trade-off of slightly lower yield than forms (i) and (ii) (Plank 2018).

\section{Self-organizing harvesting}

Modelling studies, using a size-based model, have shown that an approximation to balanced harvest across sizes in a single species emerges of its own accord if independent individual fishing agents are free to selectively target a size of their own choosing, with the goal of maximising their own biomass yield. In this case, the total fishing mortality rate (aggregated over fishers) and the production come into line without external intervention (Plank et al. 2017; Plank 2017). The model assumes that the value and cost of capture per unit biomass are constant over all sizes, a condition more likely to apply in small-scale and subsistence fisheries of developing countries than in the markets of the developed world. If individuals are incentivised to focus their fishing effort where the easiest returns are, this tends to result in high aggregate fishing mortality on high productivity species and/or sizes. This result is from a simple, stylised model, but nonetheless provides a counterpoint to arguments that the difficulty of enforcement make balanced harvest impractical (Andersen et al. 2016; Froese et al. 2016; Reid et al. 2016), at least in a non-commercial setting. However, these results do not extend to commercial multispecies fisheries with differential price for different sizes, or with different costs of capture.

The result is broadly consistent with some smallscale, African, freshwater fisheries, in which regulations are weak and fishing is primarily for yield (food) rather than profit (see "Empirical evidence" section;
Peter and van Zwieten 2018). There is no suggestion that the methods of fishing common in African inland fisheries are perfect balanced harvesting or can be transported unchanged to the industrial fisheries of developed countries.

Substitutive mortality and fisheries-induced evolution

Internalizing the mortality rate in size-spectrum models exposes the difficulty of trying to separate natural mortality rate and fishing mortality rate into two independent and additive parts $(Z=M+F)$. Removing fish of some chosen size leads to a reduction in the mortality rate of their prey to some extent (after the buffering effect of density dependence has been reached). The extra prey then increase the death rate of their own prey, and so on, which results in a trophic cascade (Andersen and Pedersen 2010) (Fig. 3). Substituting predation mortality with fishing mortality, i.e. taking out the prey that survive because of fishing on their predators, would reduce ecosystem disruption. Results from size-spectrum models show that balanced harvest comes closer to matching the natural survivorship than does a size-atentry fishery (Law et al. 2013, 2016).

There are potential longer-term gains from substitution of predation mortality by fishing mortality, via a reduction in the selection differentials on fish life histories and in the potential for fisheries-induced evolution (FIE) (Law 2000; Etnier and Fowler 2010; Heino et al. 2015). A recent model of Atlantic cod has shown that using gillnets to target more intermediatesized fish could reduce or reverse the evolutionary effects on maturation age of using trawls to target primarily large fish (Zimmermann and Jørgensen 2017). A size-spectrum model of FIE has shown that balanced harvest over sizes can substantially reduce the strong selection pressures on maturation size generated by size-at-entry fishing while maintaining yields (Law and Plank 2018).

Fishing is selective with respect to various aspects of fish behaviour (Heino and Godo 2002; Killen et al. 2015; Pauli et al. 2015; Andersen et al. 2017). Imposing moderate fishing mortality on each utilisable ecological group indicates that implementation of balanced harvest requires a diverse fishing fleet operating a wider range of fishing gears, both passive and active (Kolding and van Zwieten 2014; Reid et al. 
2016; Heath et al. 2017). Fisheries operating multiple gears probably cause less evolutionary selection on behavioral traits than those dominated by a single gear.

\section{Empirical evidence}

Balanced harvest has not yet been explicitly implemented by any management authority, and hence there is limited supporting evidence. This section therefore identifies examples of fisheries which, by their outcome, if not by their explicit planning, led to situations close to what might be expected from balanced harvest.

\section{African small-scale fisheries}

One of the few lines of empirical evidence supporting balanced harvest so far is from some small-scale inland fisheries in Africa (e.g. Bangweulu Swamps and Lake Kariba), in which the fishers, using a combination of selective individual gears, develop an emergent fishing pattern that seems to follow the production of the species and sizes caught (Kolding et al. 2003, 2015, 2016c; Kolding and van Zwieten 2011; Kolding and van Zwieten 2014). Importantly, such a fishing pattern has evolved intrinsically in spite of, or in the absence of, the conventional selectivity regulations that exist in nearly all fisheries and that often are all but ignored by fishers (Misund et al. 2002). This mirrors and supports the theoretical results of Plank et al. (2017) and Plank (2017).

\section{Bangweulu swamps}

The Bangweulu swamps in Northern Zambia are a vast oligotrophic wetland that support the second most important fishery of the country (Kolding et al. 2003, 2016c). The fishing pattern and methods have evolved into a flexible and dynamic combination of gillnets, weirs, longlines and traps, and have not changed much in recorded history, and probably centuries (McKey et al. 2016). Most of the species and sizes caught are small with a high biological turnover, but larger species are still being relatively more heavily exploited (Fig. 4), indicating that the fishing pattern is not exactly balanced harvest. The mixture of small fish, locally called 'Kapesa', is sundried and consumed whole, preserving all the micronutrients, and is environmentally friendly in that post-processing and storage requires limited fuel or energy. Technically, $80 \%$ of the fishing gears and around $90 \%$ of the catches are illegal under the current fisheries legislation that prohibits catching small fish and the use of active gear. However, due to the remoteness and inaccessibility of the area, enforcement has never been successful. A length-based multispecies stock assessment (Kolding et al. 1996) found all the small species were lightly exploited, and only a few of the larger species, caught in the legal gears, were overexploited. However, this fraction of the total catch was less than $2 \%$.

\section{Lake Kariba}

Man-made Lake Kariba on the Zambezi River, created primarily for hydroelectricity in 1958 and shared almost equally between Zambia in the north and Zimbabwe in the south is one of the world's largest reservoirs by volume. Although there is a longitudinal gradient in species composition from a lotic to a lentic environment, it is reasonable to assume that the level of primary production is similar in both sides of the lake. Although similar, the demersal fish communities of two sides of the lake are somewhat ecologically "isolated" as the inshore fish do not venture into the open water in the middle of the lake. A fishery started almost immediately in the newly inundated lake, but the management approach on the two sides took different trajectories between Zimbabwe (at that time Rhodesia) and Zambia (Kolding et al. 2003). While Zimbabwe introduced and strictly enforced conventional management regulations such as gear and mesh size limits and effort control, no such control or enforcement took place on the Zambian side. Thus, inadvertently Lake Kariba became a long-term, largescale experiment for the results of controlled management compared with virtually no management (Jul-Larsen et al. 2003). After nearly 40 years of continued fishing under these conditions, the fishing pattern and fishing intensity on the two sides of the lake had become quite different. While total effort, catch and mesh sizes remained constant in Zimbabwe, the effort and catches in Zambia increased so that by the 1990s the total catch was 6 times higher than in the controlled side of the lake. Importantly, the increase in catch and effort was accompanied by a simultaneous 


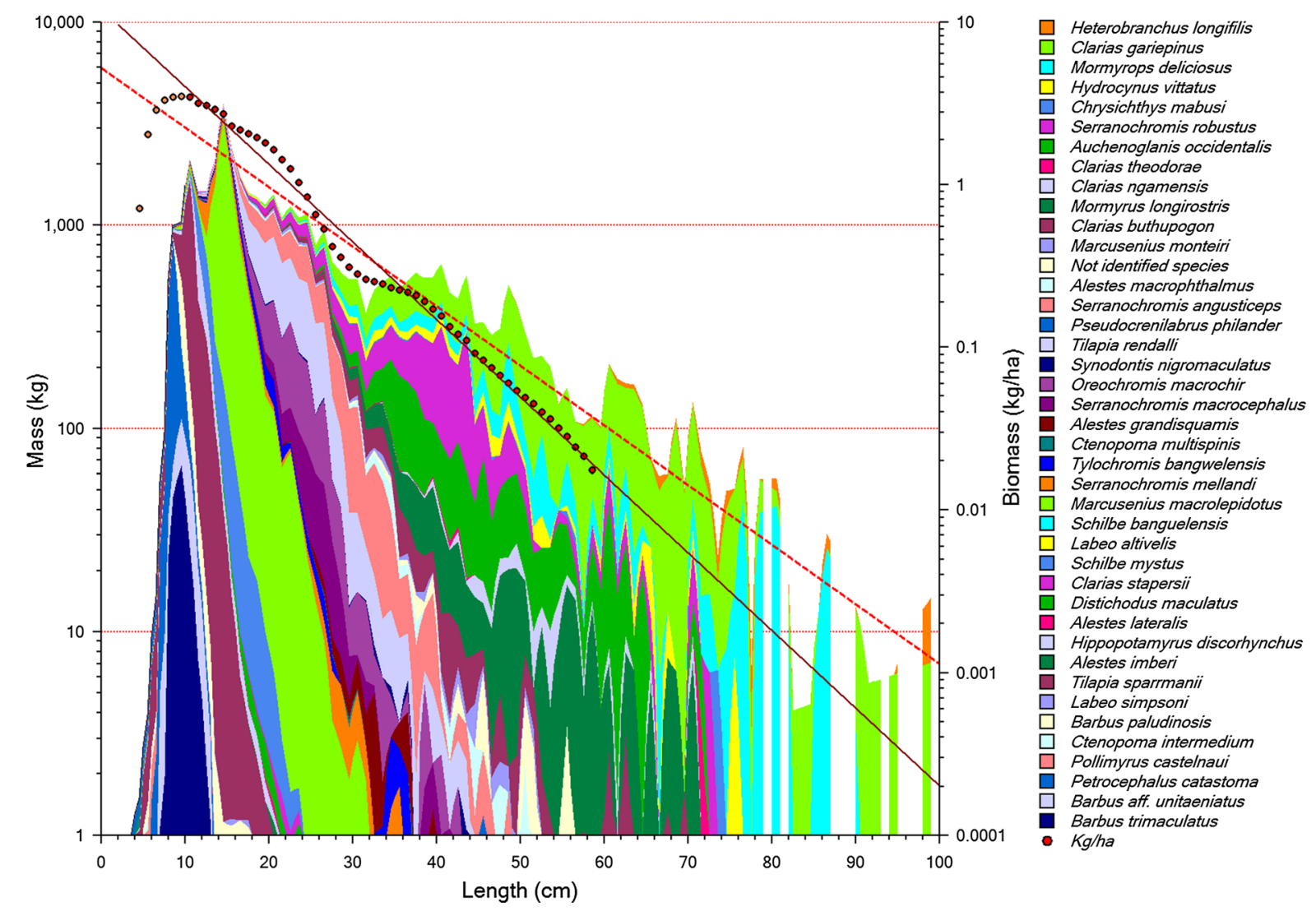

Fig. 4 Log-transformed cumulated catch (mass in kg, left $\mathrm{Y}$-axis) by species and body size $(\mathrm{cm})$ by all major fishing methods in Bangweulu (1994-1997 surveys). Each colour (shade) represents a species. Superimposed (right Y-axis, diamonds, full line) is the total log-transformed biomass-size

decrease in average mesh size, so that the fishers, while reducing the catch of larger species, were increasingly catching smaller more productive species, in a similar way to that observed in the Bangweulu fishery and simulated in the model of Plank et al. (2017). This gradual shift in mesh sizes resulted in a more even distribution of the fishing intensity across all species and sizes and thus reducing disruption to the fish community structure. This can be validated by comparing the species compositions, as well as the slopes of the biomass distributions between a fished and an unfished locality (Kolding et al. 2003, 2016c). The different fishing patterns and outcomes of the two sides of Lake Kariba have also been theoretically explored and analysed in a sizebased multispecies simulation (Kolding et al. 2015), which supported the empirical observations. distribution of the 13 most important species in $\mathrm{kg} \mathrm{ha}^{-1}$. The slope of the combined catches (broken line) is less steep than the community biomass (solid line) suggesting that larger species are still being more heavily exploited, despite having a lower productivity. (From Kolding and van Zwieten 2014)

\section{The Norwegian and Barents Sea}

The Norwegian and Barents Seas are arguably one of the world's best monitored and managed industrial fisheries (Kolding et al. 2016a). Although largely regulated by conventional single-species management with quotas and minimum size limits on adult fish only, there are multispecies considerations in setting catch levels on several of the main fisheries (cod, haddock, capelin), and the fishery targets a range of species (Howell et al. 2016). It also includes, in addition to harvest of shrimps, small pelagic fish and large demersal fish, several TLs, including harvest of copepods (Calanus finmarchicus), bird eggs, seals and whales. Overall, at the species level, the fishery reflects a system that on average is harvested in a more balanced way (i.e. across a wide range of sizes and TLs) than most marine systems (Kolding et al. 2016a) 
Fig. 5 Yield relative to production $\left(\mathrm{kg} \mathrm{km}^{-2}\right)$ for the 28 stocks or groups harvested in the Norwegian/ Barents Sea extracted from an Ecopath model for the two seas parameterized to reflect ecosystem state and fisheries in 2000. Green line is yield equal production $(\boldsymbol{Y} / \boldsymbol{P}=1)$. Dotted red line and dashed blue line are $\boldsymbol{Y} / \boldsymbol{P}=0.5$ and $\boldsymbol{Y} / \boldsymbol{P}=0.25$ respectively. Full black line is the linear regression across all species. Note that production is current production with fishing, and that only exploited species are included. From Kolding et al. (2012)

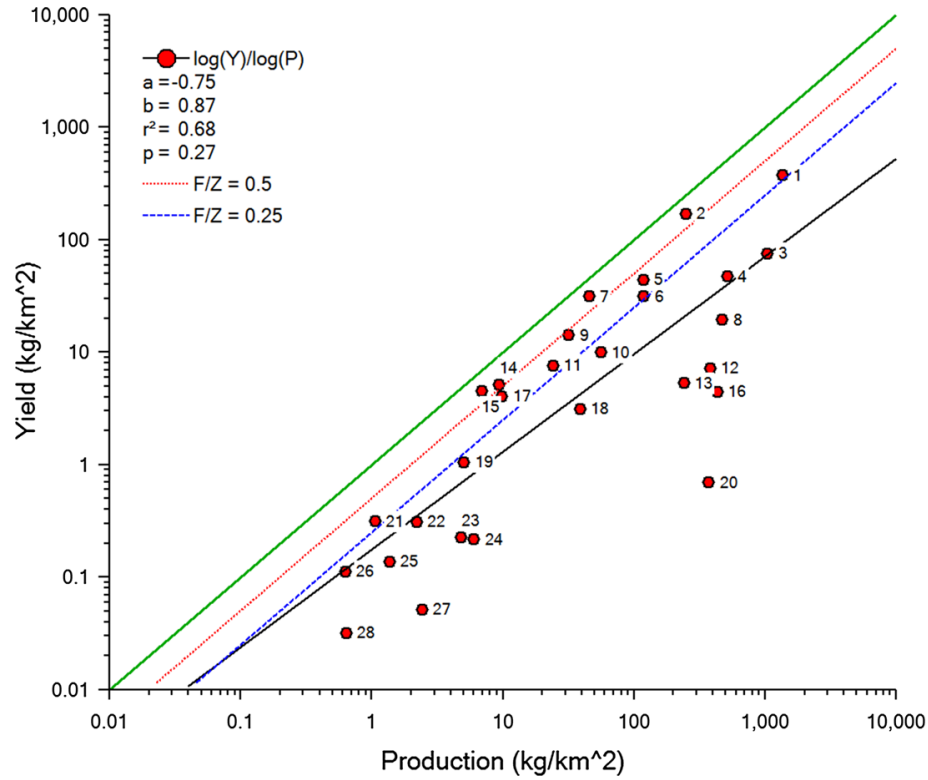

$1=$ NSS Herring $(3+)$ $2=\mathrm{NE}$ Arctic cod $(3+)$ $3=$ Capelin $(2+)$ $4=$ Blue whiting $(2+)$ $5=$ Saithe $(3+)$ $6=$ Mackerel $7=$ Haddock $(3+)$ $8=$ Prawns $9=$ Coastal cod $(3+)$ $10=$ Wolffishes $11=$ Other benthic fish $12=$ Polar cod $13=$ Small pelagic fish $14=$ Golden redfish $(5+)$ $15=$ Greenland halibut $(5+)$ $16=$ Blue whiting $(0-1)$ $17=$ Deep-sea redfish $(5+)$ $18=$ Flatfishes and rays $19=$ Lumpsucker $20=$ Edible crabs and lobster $21=$ Harp seal $(0)$ $22=$ Minke whale $23=$ Harp seal $(1+)$ 24=Other sharks $25=$ Atlantic salmon $26=$ Basking shark $27=$ Other seals $(1+)$ $28=$ Other seals $(0)$
(Fig. 5). This could, to some extent, be predicted by the dependence of the single-species MSY on productivity for each species. Nevertheless, there is a large variation in size range between species, no balance by size within species (most fisheries have a minimum catch size), a focus on fishing higher trophic level fish, and many components and size classes of the ecosystem are still not harvested, so that the overall community structure is altered. It should also be noted that harvesting on both low TL components such as zooplankton, and high TL species such as marine mammals, are highly contentious issues in some jurisdictions (Butterworth 2014). This system indicates that while CFM can be implemented and extended to include some multispecies components and produce "successful" fisheries management with some elements of balance, it does not mimic full balanced harvesting of a marine ecosystem.

The fundamental differences between small-scale fisheries in the developing world and the large-scale economic fisheries in the developed world (Kolding et al. 2014) are indicative of the potential for, and the constraints to, implementing balanced harvest. Modern economy, selective consumers, selective fisheries, variable harvesting costs, and the conventional management paradigm are strong obstacles for balanced harvest as reflected in the lack of empirical examples, and the problematic implementation (Charles et al. 2016; Garcia et al. 2016b; Howell et al. 2016; Reid et al. 2016). On the other hand, where food production is the primary motivation, then fishing patterns sharing some of the characteristics of balanced harvest have arisen naturally and proved stable and successful without the need for complex management.

\section{Economic considerations}

The potential economic costs of balanced harvest in industrial fisheries have been raised (Jacobsen et al. 2014; Zhou et al. 2015; Burgess et al. 2016; Froese et al. 2016), but a full quantitative economic evaluation of the potential costs and benefits of $\mathrm{BH}$ has yet to be conducted. Qualitatively, economic costs might come from: (1) the reduced profit in harvesting and processing a wide range of sizes and species, including investments in improved gears and strategies to catch and process them and development of new markets (Burgess et al. 2016); the possible decreased value of harvests, if the market value of increased low-value species and sizes cannot compensate for potential reductions in harvest of high-value species and sizes; (2) short-term harvest loss in large high-value species and sizes during their rebuilding phase (as in any CFM-based rebuilding plan); (3) added coordination of management plans across fleets operating on different but interaction species in the ecosystem; and (4) building a broader management structure and 
scientific knowledge base, addressing more species, tuning mixtures of gears and effort among fleets, and introducing ecosystem impact evaluation. Some of these costs would apply to any EAF strategy and need to be discussed in the context of what are necessary costs in re-establishing ecosystem structure (Kolding et al. 2016a). However the opportunity cost of increased harvest of low value fish may be specific to balanced harvest and large enough to make fisheries unprofitable in some contexts and at some scales (Burgess et al. 2017). On the other hand, there is increased focus on consuming small fish, as these contain relative more vital micro-nutrients (Beveridge et al. 2013), so market prices for such commodities may increase with a more health-conscious market.

In addition, balanced harvest may increase economic benefits from (1) increases in total yields; (2) reduced fishing cost as catch per unit effort for current commercial species increases due to their increased biomass; (3) reduced costs of management measures such as discard bans, if restrictions on the use of landed "bycatch" were reduced (Karp et al. 2019); and (4) the value of increased resource stability (Garcia et al. 2014; Charles et al. 2016).

Where fish stocks are depleted or ecosystem structure severely impacted, there may be short-term costs while benefits are mainly long-term. Many fisheries might be pushed below their break-even point if not supported during the transition phase. This, however, is a function of a recovery period in general rather than of $\mathrm{BH}$ in particular.

Many of these potential costs and benefits are speculative, since there is as yet little empirical evidence. As always, the distribution of costs and benefits-and who "wins" or "loses" from a certain course of action-matters to people at least as much as their amount and matters differently in developed and developing nations. Moreover, maintaining ecosystem structure and function has societal cost and benefit implications not easily considered under classical fishery economics, whatever harvesting strategy is followed. There is therefore further work required on the likely social and economic implications of a move to $\mathrm{BH}$ in any given ecosystem.

\section{Management implications}

The most frequently asked questions about balanced harvest pertain to potential difficulties in its implementation, in particular for large scale industrial fisheries; and it has been suggested that CFM, with modifications, may achieve the broad goals of balanced harvest in a more effective way (Burgess et al. 2016; Froese et al. 2016; Howell et al. 2016; Reid et al. 2016). Incremental improvements of CFM, including economic reforms and better enforcement and incorporating of ecosystem considerations through density dependence and variable predation mortality, are indeed producing good results in many fisheries (Hilborn 2007; World Bank 2009; Worm et al. 2009; Costello et al. 2012, 2016; OECD 2012). However, the impact of conventional fishing on ecosystem structure remains an outstanding problem in many regions, as the differential ability of States to report on the different aspects of Aichi biodiversity Target 6 (https://www.cbd.int/sp/targets) demonstrates.

Balanced harvest can be used in two complementary conceptual ways to help address the implementation problem.

(1) As a strategic guidance. Like EAF, into which it fits, balanced harvest provides a strategic direction (a "compass") for better aligning fisheries with UNCLOS and the CBD (Zhou et al. 2015; Charles et al. 2016; Garcia et al. 2016b; Howell et al. 2016; Reid et al. 2016). For example, managing commercial species and bycatch species by different policies with contrasting objectives (e.g. targeting $F=F_{\text {msy }}$ for the former and $F=0$ for the latter) is incompatible with balanced harvest. Likewise, policies that prohibit harvesting or retaining non-target species that are productive and abundant are contrary to balanced harvest, even though they might be justified by political considerations (e.g., preservation for non-retention recreational fishing). At this policy-guiding level, a lack of detailed ecological knowledge does not prevent management from moving in the desired direction.

(2) On the tactical level, "partially-balanced" harvest, within a small group of species and sizes (e.g., currently commercial species and size ranges) for which sufficient ecological 
information is available, could be possible. This is consistent with various harvest control rules under CFM. The case studies covered in the "Empirical evidence" section are good examples of partial balance (Howell et al. 2016).

In reality, no management approach can fully maintain the unfished ecosystem structure and function. Balanced harvest provides a strategy to minimize fishing impact on some functionally important aspects of ecosystem structure in several variants: balancing functional groups, balancing species $(\mathrm{sBH})$, and balance species and sizes (ssBH). These balanced harvest variants can be adaptively and partially implemented at an operational level (Charles et al. 2016; Howell et al. 2016). While BH may be an emergent property in many poorly or un-regulated fisheries, it would be more challenging to implement in more regulated cases. A broad-brushed métierbased fishing system might meet the challenge (Reid et al. 2016). A métier is a group of fishing operations targeting a specific assemblage of species, using a specific gear, during a precise period of the year and/or within a specific area (Davie and Lordan 2011; Deporte et al. 2012). Management could encourage one group of métiers while discouraging others, depending on their known species selectivity patterns, and how close we were to the $\mathrm{BH}$ objectives. Essentially, this could be seen as an effort quota for each métier aiming to reach $\mathrm{BH}$ objectives by the end of the year. If the catch rate, during a given year, was too high for a given species or number of species, then we could manage to reduce effort by those métier that preferentially caught those species. Fishing vessels could also be allowed to work in more than one métier, allowing them to switch in such a case. Combining this fleet structure with spatio-temporally explicit management using Real-Time Incentives (Kraak et al.
2012; Van Riel et al. 2015) would provide greater flexibility and potentially lower the management burden needed to make progress with this approach.

Most aquatic ecosystems have been changed over the past century by exploitation (Christensen et al. 2014). How should the balanced harvest be implemented in species assemblages whose structure has already been significantly affected by selective fishing? Theoretically, by redistributing fishing intensity, balanced harvest will eventually rebuild a balanced ecosystem structure. However, there is no empirical evidence and little hope to rebuild a usually unknown "unfished" state for an ecosystem, while depensatory phenomena and hysteresis make it highly unlikely that rebuilding of all depleted species will occur at similar rates. Furthermore, it is unlikely that fisheries have been the only drivers of ecosystem variability. Nonetheless, full-scale experiments in overfished freshwater lakes have shown that selective culling of previously unfished prey, as implied by balanced harvest, produces positive structural responses and may promote recovery of depleted predators (Persson et al. 2007). In that study, removing old stunted individuals of a prey fish species caused an increase in the availability of small sized prey and allowed the predator to recover.

Several conceptual ecosystem-level "structures" (Fig. 6) that could be used as balanced harvest norms in order to develop harvest control rules have been proposed (e.g., Andersen and Beyer 2006; Garcia et al. 2012, 2016a; Kolding and van Zwieten 2011; Kolding et al. 2016a; Law et al. 2016). To reach a normative desired ecosystem status, balanced harvest requires a definition of: (1) the management unit; (2) the norm boundaries i.e. the largest and smallest species, size or TL considered in the regulations; (3) baseline reference values for slope and intercept of the desired
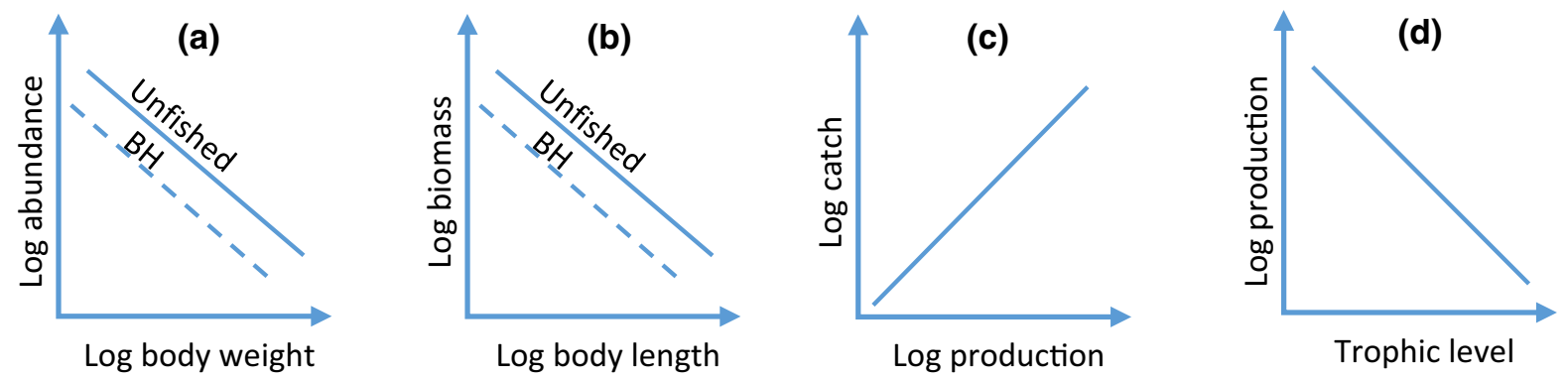

Fig. 6 Examples of potential ecosystem structures usable as BH norms, based on size, production, and trophic level 
biomass size-spectrum, consistent with UNCLOS, FSA and CBD norms; (4) an assessment of historical and current state of the ecosystem (variability, level of exploitation and unbalance); and (5) pre-agreed courses of action in different emerging conditions. Practical challenges relate to variability and signal/ noise ratios; versatility of the norm in different environments; response times of ecological and management sub-systems; capacity to detect causality in observed phenomena; and criteria for determining acceptable boundaries (Garcia et al. 2016b).

\section{Discussion and conclusions}

In this paper we have examined the background and concept of balanced harvest, results from different models, empirical evidence available, international legal and policy frameworks, economic aspects, and management implications. Clearer definition, goals, and interpretation of balanced harvest and associated terms are provided. We have also addressed some of the questions and critiques related to the concept. Since the debate on balanced harvest is ongoing, there is a series of unresolved questions and disagreements in the fisheries community and even within the group researching the concept. We begin with some remaining scientific issues that require more attention and further research.

First, implication of harvesting small immature fish as suggested by some modelling studies has raised serious critiques and questions (Froese et al. 2016; Pauly et al. 2016). Rather than disagreeing on the principle of growth overfishing, the questions hinge on the predicted size (or age) corresponding to the peak of cohort biomass (or production). The predicted peak varies among models, likely caused by differences in the way density dependence operates in models (Andersen et al. 2017). To some extent, this stems from our limited understanding of the way density dependence affects population dynamics in different ecosystems, but more importantly from our general lack of knowledge on the population dynamics of early life stages. Empirical research on ecological interactions at varying stages of life in different ecosystem could inform the optimal distribution of fishing mortality across size.

An implication of high fishing mortality rate on immature fish may also relate to how size-specific productivity is quantified. The definition of production (total cumulated new biomass produced from an ecological group during a given period) involves two key terms: "new biomass" and a unit of time. In sizebased models, productivity is essentially equivalent to size-specific somatic growth rate. This differs from productivity measured at overall population level, which includes reproductive potential. In traditional stock assessment, productivity is typically quantified by the rate of increase in total biomass (somatic growth + recruitment) between years (e.g., using surplus production models) or by the ratio between recruitment and spawning biomass (between generations, e.g., using stock-recruitment models). Such differences may lead to different recommendations about size-specific fishing mortality and deserve further consideration.

Second, one of the major critiques of balanced harvest is that empirical evidence is scarce and questionable. The limited empirical examples close to, but not equivalent to balanced harvest, are specific to the unconstrained fishing patterns and socioeconomic setting in which they have been observed. Examples of maintaining balance among a small group of commercial species under advanced CFM exist (Howell et al. 2016), using harvest control rules to fish each stock roughly according to its productivity. Conclusions drawn from empirical examples of sBH and ssBH are uncertain. For example, there is a debate whether unregulated fisheries in African are approaching balanced or unselective fishing (Tweddle et al. 2015; Froese et al. 2016; Kolding et al. 2016c). Further analysis of inland fisheries data focusing on fisheriesinduced changes in species composition would strengthen these limited empirical cases, although none of them have ever been explicitly managed for balanced harvest.

Third, difficulties in implementing balanced harvest are widely hypothesised but yet to be tested. To address this concern, several publications have shown how balanced harvest can be adopted as a strategic guidance as well as an operational tactic for fisheries management. At a strategic level, balanced harvest does not require comprehensive biological and ecological knowledge. For example, balanced harvest does not enter into the complexities of data needed in developing different policies for different categories of fish based on their market values (e.g., harvest policy for commercial species and bycatch policy for 
bycatch species). At a tactical level, implementation complexity and difficulty depend on the balanced harvest strategy adopted and increase from balancing fishing mortality across functional groups to current commercial species only (partial sBH), to including other potentially utilisable species (full $\mathrm{sBH}$ ), and to balancing across size as well as species (ssBH). If species within a functional group have similar productivities, a coarse balanced harvest at this level may be sufficient in some ecosystems. Before addressing the question of implementation difficulties, there are other relevant questions. From the point of view of fishery yield and species sustainability, how much can be gained in moving from $\mathrm{sBH}$ to ssBH? Would $\mathrm{sBH}$ be sufficient to maintain species composition while obtaining high sustainable yields? Would the implementation of ssBH in a large scale commercial fishery be economically feasible? Would a change in size selectivity from sigmoidal to dome-shaped, e.g. via slot fishing regulations (i.e. both upper and lower size limits), be a sufficient approximation to $\mathrm{ssBH}$ to provide the key benefits? The answer to any of these questions is likely to be specific to the particular fishery, socio-economic conditions, and levels of $\mathrm{BH}$ fishing intensity.

Fourth, one of the key goals of balanced harvest is to maintain ecosystem structure and function as required by $\mathrm{CBD}$ and EAF. Limited modelling studies have demonstrated that fully maintaining relative ecosystem structure comparable to unfished status is possible only when the majority of catch is taken from low trophic levels, in accordance with their higher production. Under Western dominated paradigms and social and economic conditions, there will be tradeoffs between profitability and conserving ecosystem structure. A compromising strategy is to allow some changes in community composition by imposing a relatively higher fishing mortality rate on more valuable species and sizes than on low-valued ecological groups. Such a compromise strategy lies between CFM and concentrating on low trophic levels, for example, adopting $\mathrm{BH}$ forms (i) and (ii) and accepting some changes in ecosystem structure.

Besides these context-specific questions, fisheries management is complex, involving fish biology and aquatic ecology, as well as social, economic and policy considerations. Interdisciplinary theoretical studies (involving theoretical modelling and analysing empirical data) would be desirable to demonstrate trade-offs among ecological benefits, fishery yields, economic profits, and overall social consequences when shifting toward balanced harvest. A practical way forward to engage a broader community, including stakeholders, could be to take a transdisciplinary approach in a well-studied fishery with multiple expertise to evaluate a balanced harvest strategy and appraise implementation challenges.

Based on the discussion throughout the paper, we draw the following key conclusions to address, to some extent, the questions summarized in the introduction.

(1) Balanced harvest is congruent with present legal frameworks of relevance to fisheries and broad international policy guidance governing fisheries and conservation. It explicitly bridges fisheries and conservation frameworks better than present CFM systems.

(2) Modelling studies reveal that balanced harvest can reduce disruption of the natural trophic structure of populations, reduce the risk of instability in the population dynamics, and maintain or increase the aggregate yield.

(3) A lack of broad empirical evidence to support balanced harvest is not surprising. However, there are some limited examples that appear to be close to balanced harvest in terms of catches proportional to production. Notably, using a combination of selective individual gears and catching a wide range of species and sizes, some small-scale inland fisheries produce very high yields.

(4) The extent of balanced harvest, i.e., which species and sizes should be harvested, is not only a scientific and technical question, but also a legal and normative issue.

(5) Balanced harvest has complex implications in terms of economic costs and benefits, to individual fisheries and to the whole society, depending on the extent and manner of its implementation. Benefit distribution between sectors as well as within the sector and society will need to be considered.

(6) Successful balanced harvest would lead to a moderate reduction of biomass of all ecological groups relative to unexploited states, but for the same amount of yield, balanced harvest may 
lead to higher total biomass than conventional fishing.

(7) Balanced harvest can be used as a "compass" or framework to strategically guide the development of fisheries policies towards a more explicit EAF, as well as a tactical management tool. Various variants of balanced harvest would extend, not replace CFM, in line with EAF.

Acknowledgements We thank Drs K. Andersen, M. Burgess, B. Fulton, R. Law, M. Mauritzen, K. Sainsbury, and T. Smith for their valuable contributions in the discussion and previous versions of the paper. We are also grateful to three reviewers for their careful reviews and constructive comments of an earlier version of the paper. Charles acknowledges support from the Natural Sciences and Engineering Research Council of Canada.

Open Access This article is distributed under the terms of the Creative Commons Attribution 4.0 International License (http:// creativecommons.org/licenses/by/4.0/), which permits unrestricted use, distribution, and reproduction in any medium, provided you give appropriate credit to the original author(s) and the source, provide a link to the Creative Commons license, and indicate if changes were made.

\section{References}

Allen KR (1971) Relation between production and biomass. Can J Fish Aquat Sci 28:1573-1581

Andersen KH, Beyer JE (2006) Asymptotic size determines species abundance in the marine size spectrum. Am Nat 168:54-61

Andersen KH, Pedersen M (2010) Damped trophic cascades driven by fishing in model marine ecosystems. Proc R Soc B Biol Sci 277:795-802. https://doi.org/10.1098/rspb. 2009.1512

Andersen KH, Blanchard JL, Fulton EA et al (2016) Assumptions behind size-based ecosystem models are realistic. ICES J Mar Sci 73:1651-1655. https://doi.org/10.1093/ icesjms/fsv211

Andersen KH, Jacobsen NS, Jansen T, Beyer JE (2017) When in life does density dependence occur in fish populations? Fish Fish 18:656-667. https://doi.org/10.1111/faf.12195

Benoît E, Rochet M-J (2004) A continuous model of biomass size spectra governed by predation and the effects of fishing on them. J Theor Biol 226:9-21

Berger AM, Harley SJ, Pilling GM, et al (2012) Introduction to harvest control rules for WCPO tuna fisheries. Western and Central Pacific Fisheries Commission, Management objective workshop, November 2012, Manila, Philippines

Beveridge MCM, Thilsted SH, Phillips MJ et al (2013) Meeting the food and nutrition needs of the poor: the role of fish and the opportunities and challenges emerging from the rise of aquaculture. J Fish Biol 83:1067-1084
Beverton RJH, Holt SJ (1957) On the dynamics of exploited fish populations. Chapman \& Hall, London

Breen M, Graham N, Pol M et al (2016) Selective fishing and balanced harvesting. Fish Res 184:2-8. https://doi.org/10. 1016/j.fishres.2016.03.014

Bundy A, Fanning P, Zwanenburg K (2005) Balancing exploitation and conservation of the eastern Scotian Shelf ecosystem: application of a 4D ecosystem exploitation index. ICES J Mar Sci 62:503-510. https://doi.org/10. 1016/j.icesjms.2004.12.008

Burgess MG, Diekert FK, Jacobsen NS et al (2016) Remaining questions in the case for balanced harvesting. Fish Fish 17:1216-1226. https://doi.org/10.1111/faf.12123

Burgess MG, Clemence M, McDermott GR et al (2017) Five rules for pragmatic blue growth. Mar Policy. https://doi. org/10.1016/j.marpol.2016.12.005

Butterworth A (2014) The moral problem with commercial seal hunting. Nature 508:9. https://doi.org/10.1038/509009a

Capitan JA, Delius GW (2010) Scale-invariant model of marine population dynamics. Phys Rev E 81:061901

CBD (1998) Report of the workshop on the ecosystem approach. Lilongwe, Malawi. UNEP Nairobi. Doc. UNEP/CBD/ COP/4/Inf. 9

Charles A, Garcia SM, Rice J (2016) Balanced harvesting in fisheries: economic considerations. ICES J Mar Sci 73:1679-1689

Christensen V, Walters CJ (2004) Ecopath with Ecosim: methods, capabilities and limitations. Ecol Model 172:109-139. https://doi.org/10.1016/j.ecolmodel.2003. 09.003

Christensen V, Coll M, Piroddi C et al (2014) A century of fish biomass decline in the ocean. Mar Ecol Prog Ser 512:155-166. https://doi.org/10.3354/meps 10946

Coll M, Libralato S, Tudela S et al (2008) Ecosystem overfishing in the ocean. PLoS ONE 3:e3881. https://doi.org/ 10.1371/journal.pone.0003881

Costello C, Ovando D, Hilborn R et al (2012) Status and solutions for the world's unassessed fisheries. Science 80(338):517-520. https://doi.org/10.1126/science. 1223389

Costello C, Ovando D, Clavelle T et al (2016) Global fishery futures under contrasting management regimes. Proc Natl Acad Sci USA 113:5125-5129. https://doi.org/10.1073/ pnas.0709640104

Datta S, Delius GW, Law R (2010) A jump-growth model for predator-prey dynamics: derivation and application to marine ecosystems. Bull Math Biol 72:1361-1382

Davie S, Lordan C (2011) Definition, dynamics and stability of metiers in the Irish otter trawl fleet. Fish Res 111:145-158

Deporte N, Ulrich C, Bastardie F (2012) Regional métier definition: a comparative investigation of statistical methods using a workflow applied to international otter trawl fisheries in the North Sea. ICES J Mar Sci 69:331-342

Etnier MA, Fowler CW (2010) Size selectivity in marine mammal diets as a guide to evolutionarily enlightened fisheries management. North Am J Fish Manag 30:588-603. https://doi.org/10.1577/M09-086.1

FAO (2003) Fisheries management 2: the ecosystem approach to fisheries. FAO technical guidelines for responsible fisheries, vol 4, suppl 2. Food and Agriculture Organization, Rome 
FAO (2016) The State of World Fisheries and Aquaculture 2016. Contributing to food security and nutrition for all, Rome, p 200

Froese R, Walters C, Pauly D et al (2016) A critique of the balanced harvesting approach to fishing. ICES J Mar Sci 73:1640-1650. https://doi.org/10.1093/icesjms/fsv122

Fulton EA, Smith ADM, Punt AE (2005) Which ecological indicators can robustly detect effects of fishing? ICES J Mar Sci 62:540-551

Fulton EA, Link JS, Kaplan IC et al (2011) Lessons in modelling and management of marine ecosystems: the Atlantis experience. Fish Fish 12:171-188

Garcia SM, Kolding J, Rice J, et al (2011) Selective fishing and balanced harvest in relation to fisheries and ecosystem sustainability. Report of a scientific workshop organized by the IUCN-CEM Fisheries Expert Group (FEG) and the European Bureau for Conservation and Development (EBCD) in Nagoya (Japan), 14-16 Oct 2010. IUCN and EBCD, Gland, Switzerland and Brussels, Belgium

Garcia SM, Kolding J, Rice J et al (2012) Reconsidering the consequences of selective fisheries. Science 335:10451047. https://doi.org/10.1126/science.1214594

Garcia SM, Bianchi G, Charles A et al (2014) Balanced harvest in the real world: scientific, policy and operational issues in an ecosystem approach to fisheries. IUCN, FAO, Gland

Garcia SM, Rice J, Charles A (2016a) Bridging fisheries management and biodiversity conservation norms: potential and challenges of balancing harvest in ecosystem-based frameworks. ICES J Mar Sci 73:1659-1667. https://doi. org/10.1093/icesjms/fsv230

Garcia SMM, Rice J, Charles A (2016b) Balanced harvesting in fisheries: a preliminary analysis of management implications. ICES J Mar Sci 73:1668-1678. https://doi.org/10. 1093/icesjms/fst156

Geromont BHF, Butterworth DS (2015) A review of assessment methods and the development of management procedures for data-poor fisheries. FAO Report. The Marine Resource Assessment and Management Group (MARAM), University of Cape Town, South Africa

Hartvig M, Andersen KH, Beyer JE (2011) Food web framework for size-structured populations. J Theor Biol 272:113-122. https://doi.org/10.1016/j.jtbi.2010.12.006

He P, Pol M, Suuronen P (2016) Selective fishing and balanced harvest: means, methods and implications. Fish Res 184:1. https://doi.org/10.1016/j.fishres.2016.08.015

Heath M, Law R, Searle K (2017) Scoping the background information for an ecosystem approach to fisheries in Scottish waters: review of predator-prey interactions with fisheries, and balanced harvesting. A study commissioned by Fisheries Innovation Scotland (FIS) http://www.fiscot. org/. Accessed 7 June 2019

Heino M, Godo OR (2002) Fisheries-induced selection pressures in the context of sustainable fisheries. Bull Mar Sci 70:639-656

Heino M, Pauli BD, Dieckmann U (2015) Fisheries-induced evolution. Annu Rev Ecol Evol Syst 46:461-480. https:// doi.org/10.1146/annurev-ecolsys-112414-054339

Hilborn R (2007) Defining success in fisheries and conflicts in objectives. Mar Policy 31:153-158. https://doi.org/10. 1016/j.marpol.2006.05.014
Hixon MA, Johnson DW, Sogard SM (2014) BOFFFFs: on the importance of conserving old-growth age structure in fishery populations. ICES J Mar Sci 71:2171-2185. https:// doi.org/10.1093/icesjms/fst200

Howell D, Hansen C, Bogstad B, Skern-mauritzen M (2016) Balanced harvesting in a variable and uncertain world: a case study from the Barents Sea. ICES J Mar Sci 73:1623-1631

Hsieh CH, Yamauchi A, Nakazawa T, Wang WF (2010) Fishing effects on age and spatial structures undermine population stability of fishes. Aquat Sci 72:165-178. https://doi.org/ 10.1007/s00027-009-0122-2

Jacobsen NS, Gislason H, Andersen KH (2014) The consequences of balanced harvesting of fish communities. Proc R Soc B Biol Sci 281:20132701. https://doi.org/10.1098/ rspb.2013.2701

Jacobsen NS, Burgess MG, Andersen KH (2017) Efficiency of fisheries is increasing at the ecosystem level. Fish Fish 18:199-211. https://doi.org/10.1111/faf.12171

Jørgensen C, Ernande B, Fiksen Ø (2009) Size-selective fishing gear and life history evolution in the Northeast Arctic cod. Evol Appl 2:356-370. https://doi.org/10.1111/j.17524571.2009.00075.x

Jul-Larsen E, Kolding J, Overa R, van Zwieten PAM (2003) Management, co-management or no management? FAO fisheries technical paper 426/1. Rome

Karp WA, Breen M, Borges L et al (2019) Strategies used throughout the world to manage fisheries discards-lessons for implementation of the EU Landing Obligation. In: Uhlmann S, Ulrich C, Kennelly SJ (eds) The European discard policy-reducing unwanted catches in complex multi-species and multi-jurisdictional fisheries. Springer Nature, Berlin, pp 3-29

Killen SS, Nati JJH, Suski CD, Killen SS (2015) Vulnerability of individual fish to capture by trawling is influenced by capacity for anaerobic metabolism. Proc R Soc B Biol Sci 282:20150603. https://doi.org/10.1098/rspb.2015.0603

Kolding J, van Zwieten PAM (2011) The tragedy of our legacy: how do global management discourses affect small scale fisheries in the South? Forum Dev Stud 38:267-297. https://doi.org/10.1080/08039410.2011.577798

Kolding J, van Zwieten PAM (2014) Sustainable fishing of inland waters. J Limnol 73:132-148. https://doi.org/10. 4081/jlimnol.2014.818

Kolding J, Ticheler H, Chanda B (1996) Assessment of the Bangweulu Swamps fisheries. Final Report prepared for WWF Bangweulu Wetlands Project, SNV/Netherlands Development Organisation, and Department of Fisheries, Zambia

Kolding J, Ticheler H, Chanda B (2003) The Bangweulu Swamps-a balanced small-scale multi-species fishery. In: Jul-Larsen E, Kolding J, Nielsen JR, et al (eds) Management, co-management or no management? Major dilemmas in southern African freshwater fisheries. Part 2: case studies. FAO Fisheries Technical Paper 426/2, FAO, Rome, FAO, Rome, pp 34-66

Kolding J, Béné C, Bavinck M (2014) Small-scale fisheriesimportance, vulnerability, and deficient knowledge. In: Garcia S, Rice J, Charles A (eds) Governance for marine fisheries and biodiversity conservation. Wiley-Blackwell, Hoboken, pp 317-331 
Kolding J, Law R, Plank M et al (2015) The optimal fishing pattern. In: Craig JK (ed) Freshwater fisheries ecology, 1st edn. Wiley-Blackwell, Hoboken, pp 524-540

Kolding J, Bundy A, van Zwieten PAM, Plank MJ (2016a) Fisheries, the inverted food pyramid. ICES J Mar Sci 73:1697-1713

Kolding J, Garcia SM, Zhou S, Heino M (2016b) Balanced harvest: utopia, failure, or a functional strategy? ICES J Mar Sci 73:1616-1622. https://doi.org/10.1093/icesjms/ fsw060

Kolding J, Jacobsen NS, Andersen KH et al (2016c) Maximizing fisheries yields while maintaining community structure. Can J Fish Aquat Sci 73:644-655. https://doi.org/10.1139/ cjfas-2015-0098

Kolding J, Garcia S, Rice J, Rochet M-J, Zhou S, Arimoto T, Beyer JE et al (2012) Balanced harvesting: can it reconcile fisheries and conservation objectives, and how can it be done? In: Book of Abstracts of the 6th World Fisheries Congress, 7-11 May 2012. Edinburgh, UK. PSA3.04. FSBI Conference Ltd, Glasgow, UK, pp 19

Kraak SBM, Reid DG, Gerritsen HD et al (2012) 21st century fisheries management: a spatio-temporally explicit tariffbased approach combining multiple drivers and incentivising responsible fishing. ICES J Mar Sci 69:590-601. https://doi.org/10.1093/icesjms/fss033

Larkin PA (1996) Concepts and issues in marine ecosystem management. Rev Fish Biol Fish 6:139-164

Law R (2000) Fishing, selection, and phenotypic evolution. ICES J Mar Sci 57:659-668. https://doi.org/10.1006/jmsc. 2000.0731

Law R (2007) Fisheries-induced evolution: present status and future directions. Mar Ecol Prog Ser 335:271-277. https:// doi.org/10.3354/meps335271

Law R, Plank MJ (2018) Balanced harvesting could reduce fisheries-induced evolution. Fish Fish 19:1-14. https://doi. org/10.1111/faf.12313

Law R, Plank MJ, Kolding J (2012) On balanced exploitation of marine ecosystems: results from dynamic size spectra. ICES J Mar Sci 69:602-614. https://doi.org/10.1093/ icesjms/fss031

Law R, Kolding J, Plank MJ (2013) Squaring the circle: reconciling fishing and conservation of aquatic ecosystems. Fish Fish 16:160-174. https://doi.org/10.1111/faf.12056

Law R, Plank MJ, Kolding J (2016) Balanced exploitation and coexistence of interacting, size-structured, fish species. Fish Fish 17:281-302. https://doi.org/10.1111/faf.12098

Libralato S, Coll M, Tudela S et al (2008) Novel index for quantification of ecosystem effects of fishing as removal of secondary production. Mar Ecol Prog Ser 355:107-129. https://doi.org/10.3354/meps07224

May RM, Beddington JR, Clark CW et al (1979) Managemenl of multispecies fisheries. Science 205:267-277

McCann KS, Gellner G, Mcmeans BC et al (2016) Food webs and the sustainability of indiscriminate fisheries. Can J Fish Aquat Sci 73:656-665

McKey DB, Durécua M, Pouilly M et al (2016) Present-day African analogue of a pre-European Amazonian floodplain fishery shows convergence in cultural niche construction. Proc Natl Acad Sci 113:14938-14943. https://doi.org/10. 1073/pnas.1613169114
Misund OA, Kolding J, Freon P (2002) Fish capture devices in industrial and artisanal fisheries and their influence on management. In: Hart PJB, Reynolds JD (eds) Handbook of fish biology and fisheries, vol II. Blackwell Science, London, pp 13-36

MRAG \& UNEP-WCMC (2008) Defining concepts of ecosystem structure and function for UK marine monitoring. Joint Nature Conservation Committee, Peterborough. JNCC report No. 397

OECD (2012) Rebuilding fisheries: the way forward. OECD publishing, Paris

Paloheimo JE, Dickie L (1970) Production and food supply. In: Steele JH (ed) Marine food chains. Oliver \& Boyd, Edinburgh, pp 499-527

Pauli BD, Wiech M, Heino M, Utne-Palm AC (2015) Opposite selection on behavioural types by active and passive fishing gears in a simulated guppy Poecilia reticulata fishery. J Fish Biol 86:1030-1045. https://doi.org/10.1111/jfb. 12620

Pauly D, Froese R, Holt SJ (2016) Balanced harvesting: the institutional incompatibilities. Mar Policy 69:121-123. https://doi.org/10.1016/j.marpol.2016.04.001

Persson L, Amundsen P-A, De Roos AM et al (2007) Culling prey promotes predator recovery-alternative states in a whole-lake experiment. Science 316:1743-1746. https:// doi.org/10.1126/science.1141412

Peter HK, van Zwieten PAM (2018) Operational, environmental, and resource productivity factors driving spatial distribution of gillnet and longline fishers targeting Nile-perch (Lates niloticus), Lake Victoria. J Great Lakes Res. https:// doi.org/10.1016/j.jglr.2018.10.010

Plank MJ (2017) Balanced harvesting is the bioeconomic equilibrium of a size-structured Beverton-Holt model. ICES J Mar Sci 74:112-120. https://doi.org/10.1093/ icesjms/fsw161

Plank MJ (2018) How should fishing mortality be distributed under balanced harvesting? Fish Res 207:171-174. https:// doi.org/10.1016/j.fishres.2018.06.003

Plank MJ, Kolding J, Law R et al (2017) Balanced harvesting can emerge from fishing decisions by individual fishers in a small-scale fishery. Fish Fish 18:212-225. https://doi.org/ 10.1111/faf.12172

Reid DG, Graham N, Suuronen P et al (2016) Implementing balanced harvesting: practical challenges and other implications. ICES J Mar Sci 73:1690-1696

Rindorf A, Dichmont CM, Levin PS et al (2017a) Food for thought: pretty good multispecies yield. ICES J Mar Sci 74:475-486. https://doi.org/10.1093/icesjms/fsw071

Rindorf A, Mumford J, Baranowski P et al (2017b) Moving beyond the MSY concept to reflect multidimensional fisheries management objectives. Mar Policy 85:33-41. https://doi.org/10.1016/j.marpol.2017.08.012

Scott F, Blanchard JL, Andersen KH (2014) Mizer: an R package for multispecies, trait-based and community size spectrum ecological modelling. Methods Ecol Evol 5:1121-1125

Sumaila UR, Cheung W, Dyck A et al (2012) Benefits of rebuilding global marine fisheries outweigh costs. PLoS ONE 7:e40542. https://doi.org/10.1371/journal.pone. 0040542 
Szuwalski CS, Burgess MG, Costello C, Gaines SD (2017) High fishery catches through trophic cascades in China. Proc Natl Acad Sci USA 114:717-721. https://doi.org/10.1073/ pnas. 1612722114

Trenkel VM (2018) How to provide scientific advice for ecosystem-based management now. Fish Fish 19:390-398. https://doi.org/10.1111/faf.12263

Tudela S, Coll M, Palomera I (2005) Developing an operational reference framework for fisheries management on the basis of a two-dimensional index of ecosystem impact. ICES J Mar Sci 62:585-591. https://doi.org/10.1016/j.icesjms. 2005.01.008

Tweddle D, Cowx IG, Peel RA, Weyl OLFF (2015) Challenges in fisheries management in the Zambezi, one of the great rivers of Africa. Fish Manag Ecol 22:99-111. https://doi. org/10.1111/fme.12107

United Nations [UN] (1982) United Nations Convention on the Law of the Sea

Van Riel MC, Bush SR, van Zwieten PAM, Mol APJ (2015) Understanding fisheries credit systems: potentials and pitfalls of managing catch efficiency. Fish Fish 16:453-470. https://doi.org/10.1111/faf.12066

Walters C, Christensen V, Walters W, Rose K (2010) Representation of multistanza life histories in Ecospace models for spatial organization of ecosystem trophic interaction patterns. Bull Mar Sci 86:439-459

Wolff M, Taylor MH, Tesfaye G (2015) Implications of using small meshed gillnets for the sustainability of fish populations: a theoretical exploration based on three case studies. Fish Manag Ecol 22:379-387. https://doi.org/10. 1111/fme. 12137

World Bank (2009) The Sunken Billions-the Economic Justification for Fisheries Reform. Agriculture and Rural Development. Washington, DC

Worm B, Hilborn R, Baum JK et al (2009) Rebuilding global fisheries. Science 325:578-585. https://doi.org/10.1126/ science. 1173146

Zhou S, Smith ADM (2017) Effect of fishing intensity and selectivity on trophic structure and fishery production. Mar Ecol Prog Ser 585:185-198. https://doi.org/10.3354/ meps 12402

Zhou S, Smith ADM, Punt AE et al (2010) Ecosystem-based fisheries management requires a change to the selective fishing philosophy. Proc Natl Acad Sci USA 107:9485-9489. https://doi.org/10.1073/pnas.0912771107

Zhou S, Smith ADM, Knudsen EE (2015) Ending over fishing while catching more fish. Fish Fish 16:716-722. https:// doi.org/10.1111/faf.12077

Zimmermann F, Jørgensen C (2017) Taking animal breeding into the wild: regulation of fishing gear can make fish stocks evolve higher productivity. Mar Ecol Prog Ser 563:185-195. https://doi.org/10.3354/meps11996

Publisher's Note Springer Nature remains neutral with regard to jurisdictional claims in published maps and institutional affiliations. 